\title{
Effects of Interfacial Properties between Molten Iron and Alumina on Neck Growth of Alumina Balls at Sintering in Molten Iron
}

\author{
Masashi NAKAMOTO, ${ }^{1) *}$ Toshihiro TANAKA, ${ }^{1)}$ Masanori SUZUKI, ${ }^{1)}$ Kenji TAGUCHI, ${ }^{2)}$ Yuichi TSUKAGUCHI ${ }^{2 l}$ \\ and Takaiku YAMAMOTO ${ }^{1)}$ \\ 1) Graduate School of Engineering, Osaka University, Yamadaoka 2-1, Suita, Osaka, 565-0871 Japan. \\ 2) Hasaki Research and Development Center, Nippon Steel \& Sumitomo Metal Corporation, Sunayama 16-1, Kamisu, Ibaraki, \\ 314-0255 Japan.
}

(Received on October 18, 2013; accepted on February 21, 2014)

\begin{abstract}
The effects of interfacial properties such as interfacial tension and wettability on the adhesion, agglomeration, and coalescence of inclusions on the immersion nozzle in a continuous casting process have not yet been evaluated quantitatively. In the present work, we focused on the neck growth of alumina balls at sintering because the adhesion, agglomeration, and coalescence of inclusions are regarded as being the consequence of sintering of oxides. We compared the neck growth of alumina balls at sintering in molten iron with that under an Ar gas atmosphere in order to clarify the effects of interfacial properties between alumina balls and molten iron on the sintering of alumina balls in molten iron. We found that neck growth in molten iron proceeds much faster than that under an Ar gas atmosphere. In addition, an equation for the neck growth of alumina balls in molten iron was formulated by evaluating the interfacial properties, i.e., the interfacial tension and wettability, between alumina balls and molten iron. The calculated results derived by considering the capillary phenomena of molten iron at the gap between alumina balls as the effect of wettability were in reasonable agreement with the experimental results in molten iron. These findings show that the non-wetting by molten iron of alumina balls promotes neck growth of alumina balls at sintering in molten iron.
\end{abstract}

KEY WORDS: neck growth; sintering; alumina; molten iron; wettability.

\section{Introduction}

In a continuous casting process, clogging of the immersion nozzle with inclusions is an important issue. There are thought to be three steps in the clogging of an immersion nozzle with inclusions: (1) inclusions come into contact with the nozzle, (2) inclusions adhere to the nozzle, and (3) inclusions sinter with each other to form clusters. The clogging adversely influences the operation and the product quality. Many researchers have therefore investigated the mechanism of clogging of immersion nozzles from several viewpoints. ${ }^{1-7)}$ One approach is to focus on interfacial properties such as interfacial tension and wettability. Singh ${ }^{1)}$ proposed a mechanism for alumina buildup in tundish nozzles by considering the interfacial tension between alumina inclusions and molten steel, and the wettability between them. The adherence of inclusions to the refractory surface of a nozzle occurs because the total surface or interfacial tension is minimized by the high interfacial tension between the inclusion and molten steel when the inclusion attaches to the refractory surface. Non-wetting between inclusions and molten steel makes it easier for inclusions to attach to each other by minimizing their contact area with steel.

* Corresponding author: E-mail: nakamoto@mat.eng.osaka-u.ac.jp DOI: http://dx.doi.org/10.2355/isijinternational.54.1195
Uchimura et $a l .{ }^{2}$ reported that the wettability between inclusions and molten steel and that between a refractory and molten steel are involved in the adhesion of inclusions to the refractory surface of the nozzle. They suggested that the use of an appropriate nozzle material, i.e. one which reacts with inclusions and forms low-melting oxide phases, is effective for reducing adhesion of inclusions to the refractory surface. Shinozaki et al. ${ }^{5)}$ investigated the wettabilities among a number of complex oxides, which were used as simulated inclusions, and molten iron to confirm the effects of wettability on the adhesion of inclusions. They concluded that it is possible to state qualitatively that an improvement in wettability reduces clogging of the immersion nozzle. Recently, Tsukaguchi et al. ${ }^{7}$ found that the application of an electric field between molten steel and an immersion nozzle made of alumina graphite successfully reduced clogging of the immersion nozzle by adhesion of inclusions; this is called an anti-clogging immersion nozzle. They investigated the mechanism for decreasing clogging of the immersion nozzle with inclusions to confirm that improved wettability between the molten steel and the nozzle by applying an electric field is one of the main factors in reducing clogging of an immersion nozzle with inclusions. However, a quantitative evaluation of the effect of wettability on the clogging of immersion nozzles has not yet been carried out.

Although the adhesion, agglomeration, and coalescence 
of inclusions in molten steel are geometrically different from those of inclusions on an immersion nozzle, as shown in Fig. 1, it is considered that these two behaviors resemble each other in terms of oxides contacting only with molten steel. Information on the adhesion, agglomeration, and coalescence of inclusions can therefore help the study of inclusions on immersion nozzles. There have been many studies on the adhesion, agglomeration, and coalescence of inclusions in molten steel. ${ }^{8-12)}$ The driving force for the adhesion, agglomeration, and coalescence of inclusions in liquid iron has generally been evaluated based on the interfacial properties between inclusions and molten steel, such as interfacial tension and wettability. $\mathrm{Knuppel}^{8)}$ proposed a coalescence mechanism in which a cavity is formed at the gap between inclusions, which do not wet liquid steel, when the inclusions contact each other, and the cavity generates the force to attract inclusions to each other. Braun et al. ${ }^{9)}$ reported that once two inclusions contact each other, the surface tension acting on the inclusions maintains the contact, and growth of the inclusions occurs by reduction of the surface area as the driving force. Yin et al. ${ }^{10)}$ have conducted in situ real-time observations of the collision and agglomeration behavior of inclusions on the surfaces of steel melts, using a confocal scanning laser microscope with an infrared image furnace. The agglomeration behavior of inclusions on the surface of a steel melt was revealed in considerable detail in their work. They also pointed out that capillary effects play the most important role in letting alumina particles come into contact with each other, even in a steel bath, because the processes of formation and growth of the clusters in the two cases, i.e., on the surface of a steel melt and in a steel bath, are physically the same. The influence of interfacial properties such as interfacial tension and wettability on the adhesion, agglomeration, and coalescence of

(a)

(b)

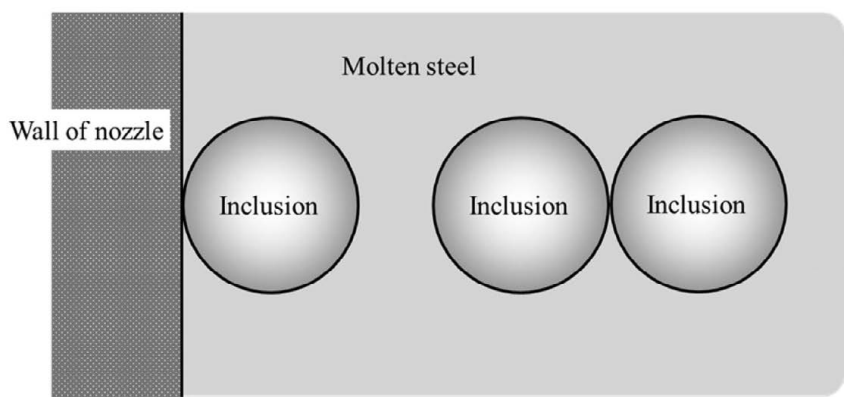

Fig. 1. Schematic diagram of (a) adhesion of inclusions to immersion nozzle and (b) coalescence of inclusions in molten steel. inclusions has often been pointed out. However, the quantitative application of static interfacial properties to dynamic phenomena such as agglomeration is difficult. The formula for the sintering of alumina particles under a gas atmosphere has therefore been directly applied to the agglomeration of alumina inclusions in molten steel in previous studies. ${ }^{11,12)}$

In the present work, the quantitative effects of the interfacial properties on the neck growth of alumina balls at sintering in molten iron were investigated to clarify the effects of the interfacial properties on the adhesion, agglomeration, and coalescence of inclusions because these phenomena are attributed to sintering of oxide inclusions. The neck growth of alumina balls at sintering in molten iron was experimentally compared with that under an Ar gas atmosphere to confirm the difference between the rates of neck growth in the areas around two alumina balls. In addition, we tried to develop a formula for the sintering of alumina balls in molten iron by evaluating the interfacial properties between alumina balls and molten iron, i.e. the interfacial tension and the wettability. We then discussed the effects of the interfacial properties on the neck growth of alumina balls in molten iron by comparing the calculated results with the experimental ones.

\section{Experimental}

\subsection{Sintering of Alumina Balls under Ar Gas Atmo- sphere}

Alumina balls $\left(\mathrm{Al}_{2} \mathrm{O}_{3} 92 \%, \mathrm{SiO}_{2} 5 \%\right)$, which were prepared by tumbling granulation, were used in the experiments. For simplicity, we assumed that this material was pure alumina. Each ball is a sintered body which composed of the particles of several hundred $\mathrm{nm}$ to several $\mu \mathrm{m}$. The average diameter of the alumina balls was $500 \mu \mathrm{m}$. Each alumina ball was observed using optical microscope to check the sphere shape and the diameter. The diameter range of the alumina balls was $300-700 \mu \mathrm{m}$. Two alumina balls were inserted in a hole of diameter $1 \mathrm{~mm}$ in a graphite block, as shown in Fig. 2(a). The atmosphere in the furnace was replaced by an Ar gas atmosphere by evacuation. The furnace was heated to the target temperature at $200 \mathrm{~K} / \mathrm{h}$ under an $\mathrm{Ar}$ gas flow of $30 \mathrm{~mL} / \mathrm{min}$ (s.t.p.). The target temperatures were 1773 and $1873 \mathrm{~K}$. The holding times at the target temperature were 24 and $48 \mathrm{~h}$ at $1773 \mathrm{~K}$, and $10 \mathrm{~h}$ at 1873 $\mathrm{K}$. After cooling to room temperature at a rate of $-200 \mathrm{~K} / \mathrm{h}$, the alumina balls were observed using a stereoscopic microscope and a scanning electron microscope. (a)

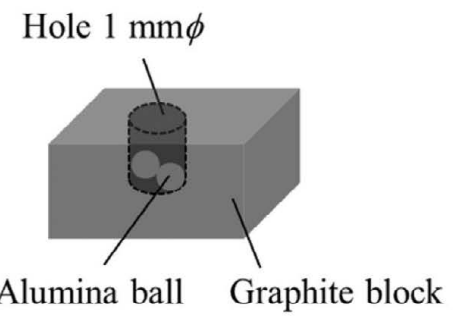

(b)

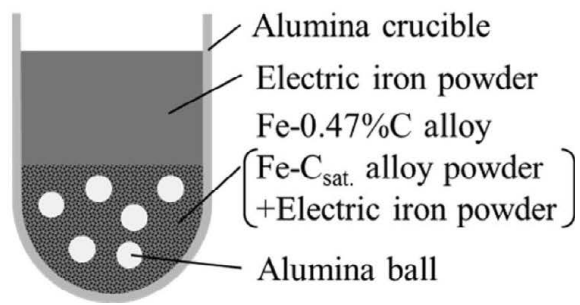

Fig. 2. Schematic diagram of experimental sample (a) under Ar gas atmosphere and (b) in molten iron. 
(a)

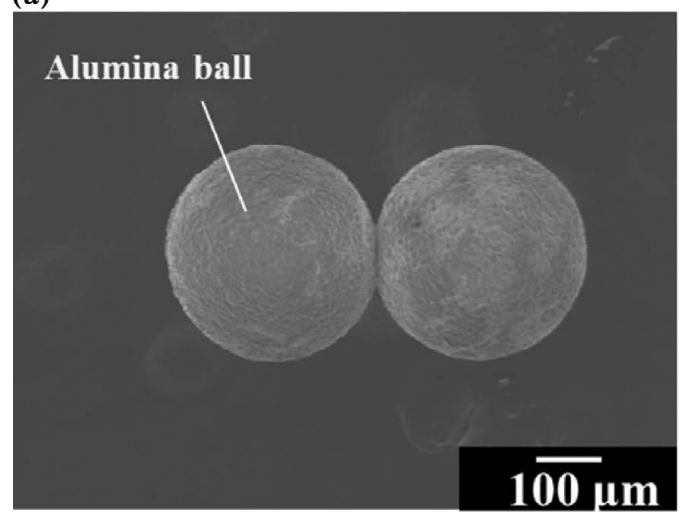

(b)

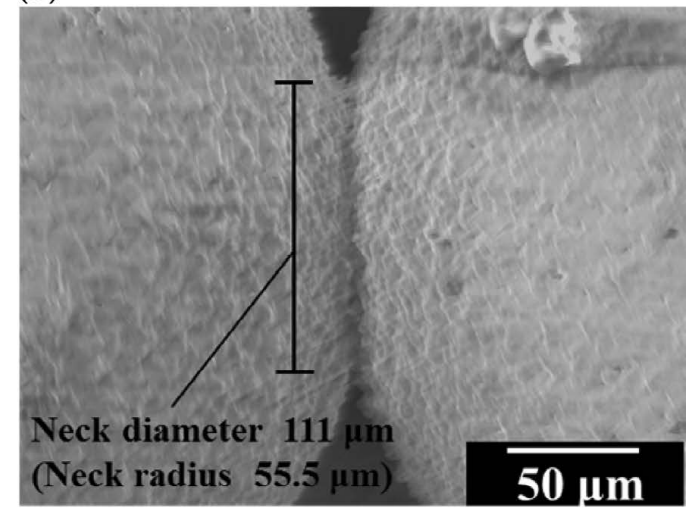

Fig. 3. (a) Appearance of alumina balls and (b) magnified image at neck part, observed using scanning electron microscope. Experimental conditions are molten iron at $1773 \mathrm{~K}$ for $10 \mathrm{~h}$.

\subsection{Sintering of Alumina Balls in Molten Iron}

The same alumina balls as those described in section 2.1 were used. An Fe- $\mathrm{C}_{\text {sat }}$ alloy premelted at $1573 \mathrm{~K}(1.00 \mathrm{~g})$ and electrolytic iron $(8.85 \mathrm{~g})$, to give $\mathrm{Fe}-0.47$ mass $\% \mathrm{C}$, were used as a liquid material. These powdered materials and 300-500 alumina balls were mixed and inserted in an alumina crucible, as shown in Fig. 2(b). Electrolytic iron powder (7.36 g) was placed above the mixture. This powder acts as a cover, to keep the alumina balls in the liquid iron. This is because the $\mathrm{Fe}-0.47$ mass $\% \mathrm{C}$ liquid is in equilibrium with solid $\delta$-Fe at $1773 \mathrm{~K}$. The atmosphere in the furnace was replaced by an Ar gas atmosphere by evacuation. The furnace was heated to $1773 \mathrm{~K}$ at $200 \mathrm{~K} / \mathrm{h}$ under an $\mathrm{Ar}$ gas flow of $30 \mathrm{~mL} / \mathrm{min}$ (s.t.p.). The holding times were 10 and $24 \mathrm{~h}$. After cooling to room temperature at a rate of -200 $\mathrm{K} / \mathrm{h}$, the iron in the sample was dissolved with hydrochloric acid to collect the insoluble alumina balls. The collected alumina balls were observed using a stereoscopic microscope and a scanning electron microscope.

\section{Results}

The appearance of the alumina balls kept in molten iron at $1773 \mathrm{~K}$ for $10 \mathrm{~h}$ is shown in Fig. 3(a) as an example. Two alumina balls are stuck together, which means that sintering of the alumina balls occurs. Figure 3(b) is a magnified image at the neck between two alumina balls. The neck radius was measured from this image. The value is $55.5 \mu \mathrm{m}$ (neck diameter $111 \mu \mathrm{m}$ ) for this sample. The neck radii of all the samples plotted against holding time are shown in Fig. 4. The neck radius of the sample kept under conditions of temperature $1773 \mathrm{~K}$ under an Ar gas atmosphere increases with increasing time, i.e., sintering of the alumina balls proceeds with time. Under an Ar gas atmosphere, the neck radius for a holding time of $10 \mathrm{~h}$ at $1873 \mathrm{~K}$ is large in comparison with that for a holding time of $24 \mathrm{~h}$ at $1773 \mathrm{~K}$. This shows that a higher temperature promotes neck growth. The neck growth in molten iron at $1773 \mathrm{~K}$ is much faster than that in an Ar gas atmosphere at $1773 \mathrm{~K}$. Despite the lower temperature, the neck in molten iron at $1773 \mathrm{~K}$ also grows faster than that in an Ar gas atmosphere at $1873 \mathrm{~K}$. These results show that neck growth between alumina balls, i.e., sintering between alumina balls, in molten iron is faster than in an Ar gas atmosphere.

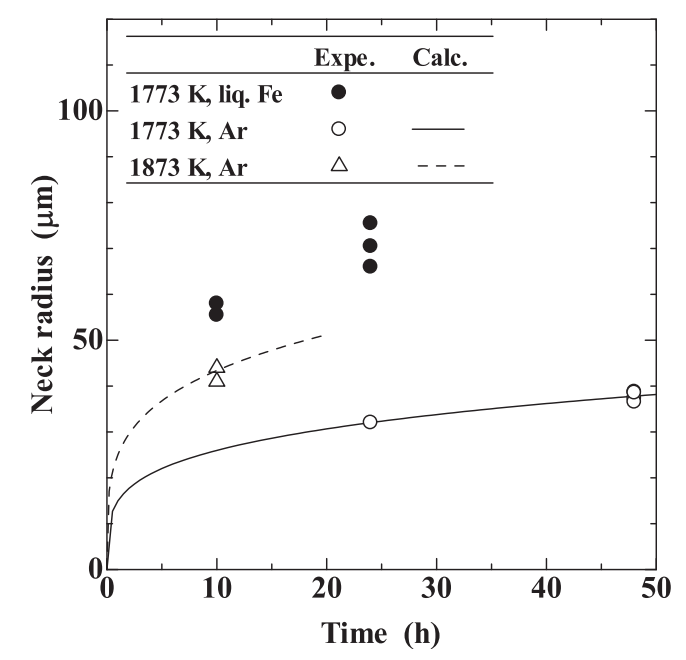

Fig. 4. Changes in neck radius with time.

\section{Discussion}

\subsection{Equation for Neck Growth of Alumina Balls under Ar Gas Atmosphere}

The theory of the kinetic growth of necks between spheres undergoing sintering has already been developed. The relationship between the neck radius, $x(\mu \mathrm{m})$, and time, $t(\mathrm{~h})$, is expressed as ${ }^{13-15)}$

$$
\frac{x^{m}}{a^{n}}=A(T) \cdot t
$$

where $a$ is the radius of the particle. The exponents $m$ and $n$ identify the sintering mechanism: $m=2$ and $n=1$ indicate viscous or plastic flow, $m=3$ and $n=1$ represent evaporation and condensation, $m=4-5$ and $n=1-2$ represent volume diffusion, and $m=6-7$ and $n=2-3$ represent surface diffusion. The sintering mechanism can be determined by plotting the logarithm of $x$ against the logarithm of $t$ and determining the slope $1 / m$, assuming that $a$ and $A(T)$ are constant. Figure 5 shows the $\log -\log$ plot of Eq. (1) for the results under an Ar atmosphere at $1773 \mathrm{~K} ; 1 / m=0.228$, i.e. $m=4.4$, is obtained from Fig. 5. Although the value of $n$ is unknown, the value of $m$ is within the value for volume diffusion. The sintering mechanism of alumina balls in this study was therefore regarded as volume diffusion based on 
the value of $m . A(T)$, which is a temperature-dependent constant, is given as Eq. (2).

$$
A(T)=\frac{K \gamma_{\mathrm{s}} V_{0} D}{R T}
$$

where $K$ is a constant depending on the geometry of the sample and on the diffusion path, $\gamma_{s}$ is the surface tension of the material, $V_{0}$ is the molar volume, $D$ is the self-diffusion coefficient of the material, $R$ is the gas constant, and $T$ is the temperature. Combining Eqs. (1), (2), and $1 / m=0.228$ gives Eq. (3).

$$
x=\left(\frac{a^{n} K \gamma_{s} V_{0} D}{\mathrm{R} T}\right)^{0.228} \cdot t^{0.228}
$$

When fitting Eq. (3) to the time dependence of the neck radius under an $\mathrm{Ar}$ gas atmosphere at $1773 \mathrm{~K}$,

$$
\left.\left(\frac{a^{n} K \gamma_{s} V_{0} D_{1773}}{R T}\right)^{0.228}\right|_{\mathrm{Ar}, 1773 \mathrm{~K}}=15.6
$$

was obtained. The fitting curve is in good agreement with the experimental data in Fig. 4.

However, the alumina balls used in this study consist of the particles of several hundred $\mathrm{nm} \sim$ several $\mu \mathrm{m}$ as mentioned above and it is necessary to consider the validity of application of Eq. (1) to the sintering of this kind of materials. There are a lot of grain boundaries in the alumina ball, which predicts that these grain boundaries can affect the neck growth of alumina balls. For example, the increase of grain boundaries can enhance the grain boundary diffusion. If this significantly affects the neck growth of alumina balls, the sintering mechanism determined above, i.e. volume diffusion, is controversial. Therefore, the effect of grain boundary on the major diffusion processes in alumina was discussed here. It has been reported that in single-crystal alumina bulk diffusion coefficient of oxygen ion is much smaller than that of aluminum ion, ${ }^{16)}$ which means that oxygen ion bulk diffusion is rate controlling for the sintering of alumina balls with small amount of grain boundaries. On the other hand, it was revealed that preferential promotion of oxygen ion diffusion in grain boundary occurs when increasing the grain boundaries with decreasing the grain size. ${ }^{17)}$ Especially, for grain sizes smaller than $20 \mu \mathrm{m}$, the grain boundary diffusion of oxygen ion becomes faster than the bulk diffusion of aluminum ion, which makes the bulk diffusion of aluminum ion a rate controlling for the sintering of alumina balls. In addition, Coble ${ }^{18)}$ found that the main sintering mechanism is volume diffusion from the results of shrinkage experiment with alumina particles of $200 \mathrm{~nm}$. From these results, it is concluded that the bulk diffusion of aluminum ion is the major mechanism for sintering alumina balls in the present work where the alumina ball is a sintered body which composed of the particles of several hundred $\mathrm{nm}$ to several $\mu \mathrm{m}$. This agrees with the determined sintering mechanism in the present work. The other factor, which can be caused by the increase of grain boundaries and affect the neck growth, is a grain boundary energy. Although the grain boundary energy is generally regarded as a driving force for sintering, it is not included in Eq. (1). From this view point, it is possible that Eq. (1) cannot reproduce the experimental result if the effect of the enhancement of grain boundary energy affects the behavior of neck growth. However, this is considered to be unlikely because the time dependence of neck growth is reasonably fitted by Eq. (1) and, in addition, the sintering mechanism obtained in the present work is reasonable as mentioned above. Other possibilities are that the effect of grain boundary energy is incorporated in term $A(T)$ in Eq. (1) and the enhancement of grain boundaries does not affect neck growth in terms of grain boundary energy. Although both points cannot be discussed based on our experimental data, the application of Eq. (1) to the analysis in the present work, where the alumina balls composed of the particles of several hundred $\mathrm{nm} \sim$ several $\mu \mathrm{m}$ are used, is considered to be reasonable because Eq. (1) reproduces the experimental data regardless of the two possibilities.

When the temperature rises from $1773 \mathrm{~K}$ to $1873 \mathrm{~K}$, it is assumed that only the diffusion coefficient $D$ varies with temperature and the other parameters, i.e. $a^{n}, K, \gamma_{s}$, and $V_{0}$, hardly change. This is because the diffusion coefficient changes exponentially with temperature, based on an Arrhenius-type equation. From this, $\left(a^{n} K \gamma_{s} V_{0} D / \mathrm{R} T\right)^{0.228}$ under an Ar gas atmosphere at $1873 \mathrm{~K}$ is calculated using the relationship $D=D_{0} \exp \{-Q /(\mathrm{R} T)\}$, where $D_{0}$ is a frequency factor and $Q$ is the activation energy of the self-diffusion coefficient of $\mathrm{Al}_{2} \mathrm{O}_{3}$ :

$$
\begin{aligned}
& \left.\left(\frac{a^{n} K \gamma_{s} V_{0} D}{R T}\right)^{0.228}\right|_{\mathrm{Ar}, 1873 \mathrm{~K}}=\left.\left(\frac{a^{n} K \gamma_{s} V_{0} D}{R T}\right)^{0.228}\right|_{\mathrm{Ar}, 1773 \mathrm{~K}} \\
& \cdot\left\{\frac{1773}{1873} \cdot \exp \left[Q / \mathrm{R}\left(\frac{1}{1773}-\frac{1}{1873}\right)\right]\right\}^{0.228}=24.4
\end{aligned}
$$

There are a lot of data on the activation energy for the diffusion coefficient of $\mathrm{Al}_{2} \mathrm{O}_{3}$ compiled in Refs. 16), 19) and 20). Here, the activation energy of $607 \mathrm{~kJ} / \mathrm{mol}$ for neck growth obtained by Coble ${ }^{18)}$ was selected. The calculated result using the values in Eq. (5) is shown in Fig. 4. The calculation curve agrees well with the neck radius change under an Ar gas atmosphere at $1873 \mathrm{~K}$. This result shows that it is reasonable to apply Eq. (3) to the neck growth of alumina balls at sintering under an Ar atmosphere in the present work.

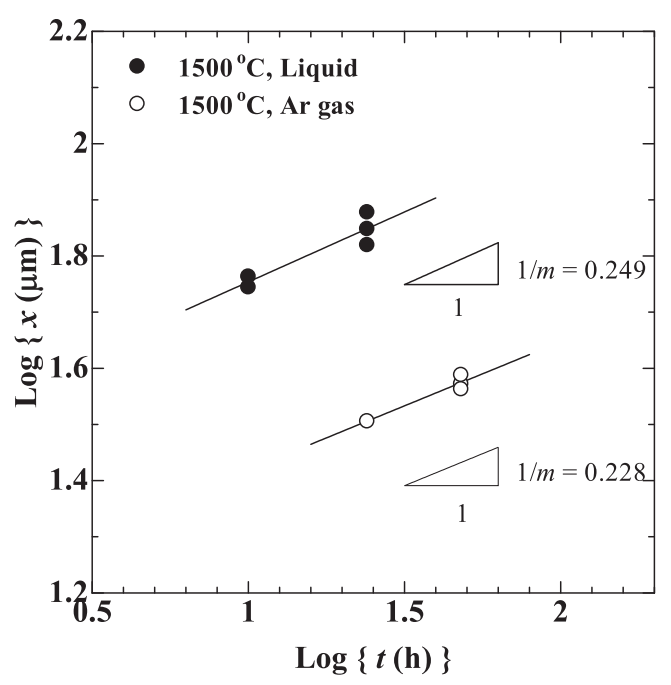

Fig. 5. Relationship between logarithm of $x$ and logarithm of $t$. 


\subsection{Equation for Neck Growth of Alumina Balls in Molten Iron}

The sintering treated here occurs in liquid phase, which may imply that liquid-phase sintering occurs in the present experiment. However, non-wetting between alumina and molten iron in the present system does not satisfy one of the necessary requirement for Liquid-phase sintering; good wetting of a solid substance by a liquid. ${ }^{21)}$ Thus, liquid-phase sintering does not occur in the present work. The relationship between the logarithm of $x$ and the logarithm of $t$ for the result in molten iron at $1773 \mathrm{~K}$ is plotted in Fig. 5 in a manner similar to the result under an Ar atmosphere at 1773 $\mathrm{K}$. The slope for the result in molten iron shows $1 / \mathrm{m}=$ 0.249 , i.e. $\mathrm{m}=4.0$, which indicates that the sintering mechanism of alumina balls in molten iron is the volume diffusion as long as under an Ar atmosphere at $1773 \mathrm{~K}$. In this regard, however, the modelling of the neck growth of alumina balls in molten iron was conducted based on Eq. (3) derived from the analysis of the result under an Ar atmosphere at $1773 \mathrm{~K}$ in order to give consistency to the equation for describing the neck growth of alumina balls. In order to evaluate the velocity of the neck growth of alumina balls in molten iron, we proposed two models for describing the neck growth in molten iron; the models include the effect of interfacial properties between solid alumina and molten iron. We performed calculations using the models. The interfacial properties considered here are the interfacial tension between solid alumina and molten iron and the wettability between these.

\subsubsection{Model Considering Interfacial Tension between Solid Alumina and Molten Iron}

Singh ${ }^{1)}$ reported that the adhesion of inclusions to the refractory surface of a nozzle occurs as a result of minimization of the total surface or interfacial tension, i.e., the surface or interfacial area. From this theory, it is considered that the driving force for the sintering of alumina balls in this study is the result of the total surface tension of alumina under an Ar gas atmosphere or interfacial tension between alumina balls and molten iron in molten iron tending to decrease. Here, we simply considered that the Ar gas around the alumina balls in the sintering experiments under an $\mathrm{Ar}$ gas atmosphere is replaced by molten iron in the sintering experiments in molten iron, i.e. the surface of the alumina ball becomes the interface between the alumina ball and molten iron. Based on this concept, Eq. (3) was rewritten by replacing the surface tension, $\gamma_{s}$, with the interfacial tension, $\gamma_{s / L}:$

$$
x=\left(\frac{a^{n} K \gamma_{s / L} V_{0} D}{\mathrm{R} T}\right)^{0.228} \cdot t^{0.228}
$$

where $\left(a^{n} K \gamma_{s / L} V_{0} D / \mathrm{R} T\right)^{0.228}$ is calculated as

$$
\left(\frac{a^{n} K \gamma_{s / L} V_{0} D}{\mathrm{R} T}\right)^{0.228}=\left(\frac{a^{n} K \gamma_{s} V_{0} D}{\mathrm{R} T}\right)^{0.228} \cdot\left(\frac{\gamma_{s / L}}{\gamma_{s}}\right)^{0.228}=18.4 \cdots(7)
$$

The average of the data obtained by Allen et al. ${ }^{22)}$ and Ebehart $^{23)}$ was used as the surface tension of the material particle, i.e. the surface tension of solid alumina, $\gamma_{s}$. The values of $1050 \mathrm{mN} / \mathrm{m}$ from Ebehart and $945 \mathrm{mN} / \mathrm{m}$ from Allen lead to $997.5 \mathrm{mN} / \mathrm{m}$. On the other hand, the interfacial ten-

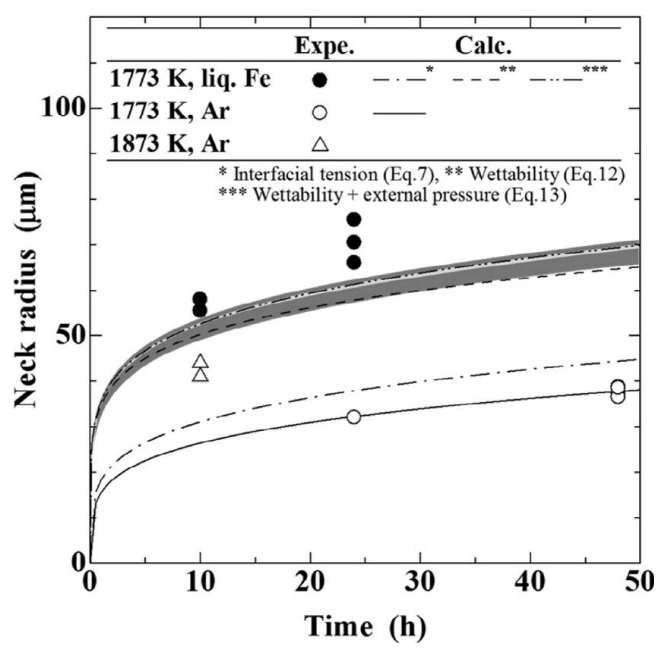

Fig. 6. Comparison of neck radius changes in experiments and neck radius changes calculated by considering *) the interfacial tension of liquid iron/alumina (Eq. (7)), **) the wettability of liquid iron/alumina (Eq. (12)), and ***) the wettability of liquid iron/alumina and external pressure (Eq. (13)).

sion between solid alumina and molten iron at $1773 \mathrm{~K}$ is not available. The value of $2050 \mathrm{mN} / \mathrm{m}$ obtained by Nogi et $a l^{24)}$ at $1873 \mathrm{~K}$ was therefore used here. The calculation curve with the values in Eq. (7) is shown in Fig. 6. The calculated result is higher than the experimental value under an Ar gas atmosphere at $1773 \mathrm{~K}$. however, it is much lower than the experimental value in molten iron at $1773 \mathrm{~K}$. These results show that the replacement of the surface tension in the equation for the sintering rate by the interfacial tension to reflect the change in the surroundings of the alumina balls, i.e. from an Ar atmosphere to molten iron, does not enable evaluation of the neck growth at sintering of alumina balls in molten iron.

\subsubsection{Model Considering Wettability between Solid Alu- mina and Molten Iron}

In addition to the idea that minimizing the total surface tension or interfacial tension provides the driving force for alumina buildup in a tundish nozzle, Singh ${ }^{1)}$ stated that the non-wetting properties between alumina inclusions and molten steel promotes the attachment of inclusions to each other by minimizing their contact area with steel. There has been some research on the effects of the wettability between a particle and a liquid on the interactive force in pressing particles together in the liquid. As mentioned in the introduction, Knuppel et al. ${ }^{8)}$ proposed that a cavity is formed at the gap between two particles in a liquid as a result of poor wettability between the particle and the liquid, and the negative pressure of the cavity can generate the force to press the particles together. Based on this concept, they suggested that this force promotes the sintering and gathering of inclusions in molten steel. As support for Knuppel's concept, Yaminsky et l. $^{25)}$ also suggested that a liquid that does not wet a material particle is spontaneously expelled from the narrow gap between two particles immersed in the liquid to form a meniscus (vapor-filled cavity) around the contact zone, and, in addition, a contracting force is applied to the particles by the meniscus. Yaminsky et al. confirmed the 
formation of a cavity and the generation of a contracting force in experiments with mercury at room temperature. Although it is expected that non-wettability increases the sintering velocity of alumina particles in molten iron in the present work based on the above research, the equation for the effect of the wettability between a particle and a liquid on the neck growth of particles in the liquid at sintering has not yet been derived. In this study, therefore, we tried to formulate the equation for neck growth of particles in a liquid that includes the effect of wettability between a particle and a liquid on the interactive force acting on the particles.

First, the interactive force generated by wettability was evaluated. As Knuppel et al. and Yaminsky et al. reported, a liquid tends to be extracted from the gap between particles when the particles in the liquid contact each other and the liquid does not wet the particle. It is therefore reasonable to consider that this behavior is attributable to capillary phenomena, i.e. capillary forces. Here, we assumed that at the microscale, the capillary phenomena at the gap between particles are same as those between two plates.

In this case, the capillary force is expressed as Eq. (8).

$$
\Delta P=P_{1}-P_{2}=-\frac{2 \gamma_{\mathrm{L}} \cdot \cos \theta}{H}
$$

$\gamma_{\mathrm{L}}$ is the surface tension of the liquid, $\theta$ is the contact angle between a particle and a liquid, and $H$ is the capillary size, i.e. the gap between particles around a contact point. $\Delta P$ is the difference between the pressure in the liquid, $P_{1}$, and the pressure in the gap formed by the capillary phenomena, $P_{2}$. Figure 7 shows a schematic diagram of a situation where two particles are in contact in a liquid. $\Delta P$ is positive when the liquid does not wet the particle $\left(\theta>90^{\circ}\right)$, which means that the pressure in the liquid, $P_{1}$, is higher than the pressure in the gap formed by the capillary phenomena, $P_{2}$. This pressure difference acts as a contracting force.

The expression for the neck growth of particles at sintering under pressure has been derived as Eq. (9), using Coble's idea: ${ }^{26)}$

$$
x=\left\{\frac{a^{n} K V_{0} D}{R T}\left(\gamma_{\mathrm{S}}+\Delta P \frac{a}{\pi}\right)\right\}^{0.228} \cdot t^{0.228}
$$

$\Delta P$ is replaced by Eq. (8).

$$
\begin{aligned}
x & =\left\{\frac{a^{n} K V_{0} D}{R T}\left[\gamma_{\mathrm{S}}+\left(-\frac{2 \gamma_{\mathrm{L}} \cdot \cos \theta}{H}\right) \cdot \frac{a}{\pi}\right]\right\}^{0.228} \cdot t^{0.228} \\
& =\left(\frac{a^{n} K \gamma_{\mathrm{S}} V_{0} D}{R T}\right)^{0.228}\left\{1+\left(-\frac{2 \gamma_{\mathrm{L}} \cdot \cos \theta}{H}\right) \cdot \frac{a}{\pi \gamma_{\mathrm{S}}}\right\}^{0.228} \cdot t^{0.228} \ldots
\end{aligned}
$$

where $\left(a^{n} K \gamma_{s} V_{0} D / \mathrm{R} T\right)^{0.228}$ is $\left.\left(a^{n} K \gamma_{s} V_{0} D / \mathrm{R} T\right)^{0.228}\right|_{\mathrm{AR}, 1773 \mathrm{~K}}=$ 15.6. Equation (10) means that the neck growth of particles at sintering in molten iron under the pressure of capillary phenomena can be calculated when the surface tension of the liquid, $\gamma_{\mathrm{L}}$, the contact angle between the liquid and a particle, $\theta$, the capillary size, $H$, the radius of the particle, $a$, and the surface tension of the particle material, $\gamma_{\mathrm{S}}$, are known. However, it is difficult to determine the capillary size, $H$, directly. Here, therefore, we assume that the capillary size, $H$, is same as the diameter of the neck curvature, i.e. $H=$ $2 \rho$, where $\rho$ is the radius of the neck curvature. Kingery et $a l .{ }^{27)}$ reported that the radius of the neck curvature, $\rho$, is

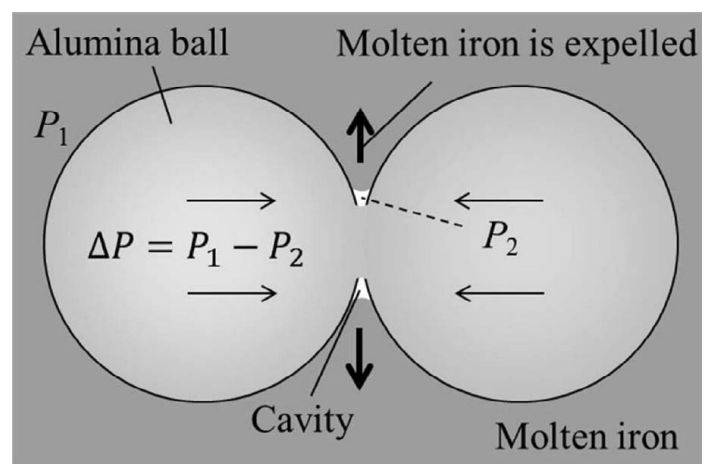

Fig. 7. Schematic diagram of contacted alumina balls in molten iron.
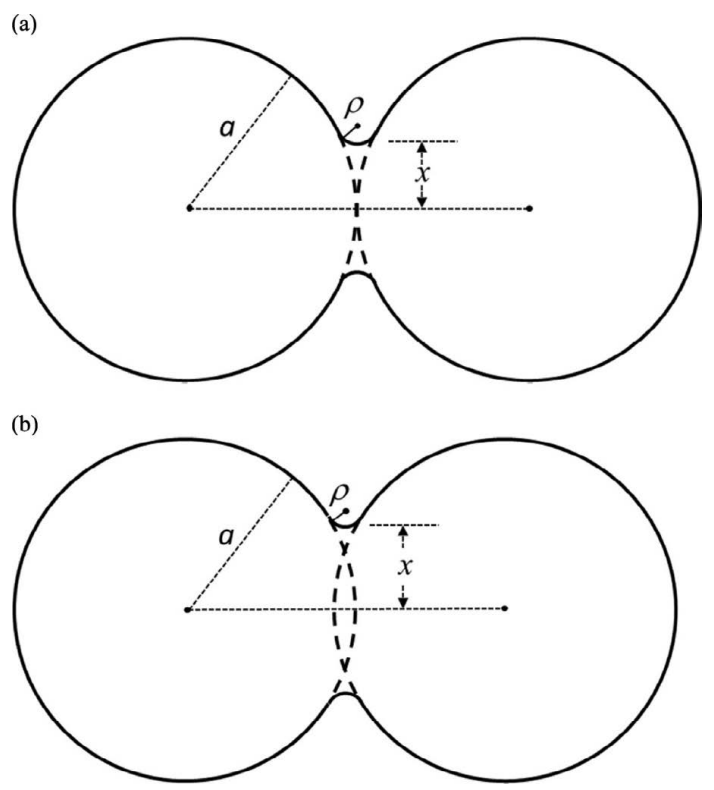

Fig. 8. Models for sintering of spheres. Sintering occurs (a) by material filling spaces between spheres and (b) by centers of spheres approaching each other.

expressed by the neck radius, $x$, and the radius of the particle, $a$. They considered two models for the rate of volume diffusion, expressed in terms of the geometric changes at sintering of spherical particles, as shown in Fig. 8, and the corresponding relationships among the radius of the neck curvature, $\rho$, the neck radius, $x$, and the radius of the particle, $a$. It is generally considered that there is an excess vacancy concentration underneath a highly curved neck surface. Neck growth can occur by replacing these vacancies by atom diffusion from inside the system. The vacancies diffuse in the opposite direction to the atoms and are eliminated on the surface of the system away from the neck in the case shown in Fig. 8(a). The distance between the centers of the spheres does not change in this case. In Fig. 8(b), in contrast, a grain boundary between the particles acts as a sink for vacancies, which decreases the distance between the centers of the spheres with time. We found that the distance between the centers of the alumina balls is less than the sum of the radii of the alumina balls, from observations of samples in our experiments. These results show that the sintering in our study behaves as shown in Fig. 8(b), which gives the relationship: 


$$
\rho=x^{2} / 4 a
$$

The capillary sizes estimated using Eq. (11), i.e. $H=2 \rho=$ $x^{2} / 2 a$, are shown in Table 1. The neck radius, $x$, and the radius of the particle, $a$, obtained in the experiments are used in this estimation. We selected the average particle radius, $160 \mu \mathrm{m}$, as $a$. The estimated neck radii are roughly $10 \mu \mathrm{m}$ for $10 \mathrm{~h}$ and $15 \mu \mathrm{m}$ for $24 \mathrm{~h}$. The magnified images of the neck parts of the samples in molten iron at $1773 \mathrm{~K}$ for 10 and $24 \mathrm{~h}$ are shown in Fig. 9. It is impossible to determine the position where we should obtain a capillary size and the capillary size exactly. However, it seems that the capillary sizes of all the samples are 5-15 $\mu \mathrm{m}$, assuming that the position is near the neck. Although the estimated capillary sizes are slightly bigger than the capillary sizes predicted from observations, they correspond reasonably to each other. By substituting $H=2 \rho=x^{2} / 2 a$ into Eq. (10), we get

$$
x=\left(\frac{a^{n} K \gamma_{\mathrm{S}} V_{0} D}{R T}\right)^{0.228}\left\{1+\left(-\frac{4 a \gamma_{\mathrm{L}} \cdot \cos \theta}{x^{2}}\right) \cdot \frac{a}{\pi \gamma_{\mathrm{S}}}\right\}^{0.228} \cdot t^{0.228 \ldots}
$$

The surface tension of pure iron suggested by Keene et al. ${ }^{28)}$ was used as the surface tension of the liquid, $\gamma_{\mathrm{L}}$. Here, we assumed that the surface tension of the liquid material in the experiment is same as the surface tension of pure iron, since the effect of carbon on the surface tension of iron is quite small, ${ }^{29)}$ and the amount of carbon in the liquid is small, although the liquid iron in the experiments contains a small amount of $\mathrm{C}$. Their suggested equation for pure liquid iron is $\gamma_{\mathrm{L}}=1909-0.52(T-1803)$. A value of $1925 \mathrm{mN} / \mathrm{m}$ at $1773 \mathrm{~K}$ was obtained using the equation. The contact angle between molten iron and an alumina particle is $130^{\circ}$, which is the average of the value of the contact angles between liquid iron and an alumina substrate, without the two clearly low values, in the compilation made by Keene in the Slag Atlas. ${ }^{30)}$ The contact angle of $130^{\circ}$ means non-wetting of molten iron on alumina particles. The surface tension of solid alumina, $\gamma_{\mathrm{S}}$, and the particle radius, $a$, are $997.5 \mathrm{mN} / \mathrm{m}$ and $160 \mu \mathrm{m}$, respectively, as used above. The calculated neck growth curve based on Eq. (12) is shown in Fig. 6. The equation was numerically solved because the variable $x$ is included in both sides of the equation. The calculation results obtained by considering the wettability reproduced the time dependence of the neck radius of alumina particles in liquid iron much better than those obtained by considering the interfacial tension.

Yaminsky et al. ${ }^{25)}$ reported that the difference between the vapor pressure in the cavity and the external pressure, i.e. atmospheric pressure, $P^{\prime}$, provides a force to press the spheres in a liquid in addition to the interactive force caused by non-wetting. Here, a term for the force generated by the difference between the vapor pressure in the cavity and the external pressure was also introduced into the model in the same way as the capillary force, as shown in Eq. (13). $x=$

$\left(\frac{a^{n} K \gamma_{\mathrm{S}} V_{0} D}{R T}\right)^{0.228}\left\{1+\left(\Delta P^{\prime}-\frac{4 a \gamma_{\mathrm{L}} \cdot \cos \theta}{x^{2}}\right) \cdot \frac{a}{\pi \gamma_{\mathrm{S}}}\right\}^{0.228} \cdot t^{0.228}$

where $\Delta P^{\prime}$ is defined as (atmospheric pressure) - (vapor pressure in the cavity). By assuming that the vapor pressure in the cavity is generated from the liquid iron, the vapor
Table 1. Estimated capillary size evaluated from $H=2 \rho=x^{2} / 2 a$. Experimental conditions are molten iron at $1773 \mathrm{~K}$.

\begin{tabular}{cc}
\hline Holding time $(\mathrm{h})$ & Estimated capillary size, $\mathrm{H}=2 \rho=x^{2} / 2 a(\mu \mathrm{m})$ \\
\hline 10 & 9.6 \\
10 & 10.5 \\
24 & 13.6 \\
24 & 17.8 \\
24 & 15.5 \\
\hline
\end{tabular}

(a)

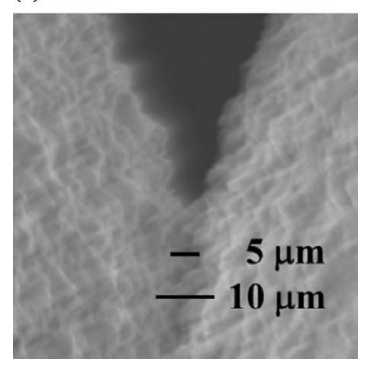

(c)

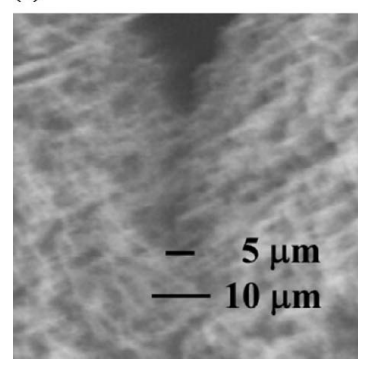

(b)

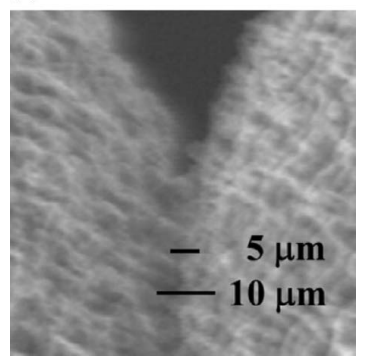

(d)

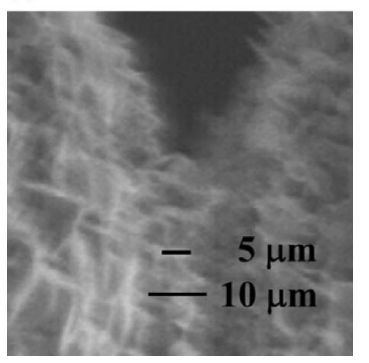

Fig. 9. Magnified image of neck part for capillary size observation. Experimental conditions are molten iron at $1773 \mathrm{~K}$ for (a) $10 \mathrm{~h}$ and (b)-(d) $24 \mathrm{~h}$.

pressure in the cavity is calculated using Kelvin's equation:

$$
\ln \frac{P}{P_{0}}=-\frac{2 \gamma V_{m}}{r \mathrm{R} T}
$$

The Kelvin equation describes the change in vapor pressure caused by a curved liquid/vapor interface of radius $r . P$ is the actual vapor pressure, $P_{0}$ is the saturated vapour pressure, $\gamma$ is the surface tension of the liquid, and $V_{m}$ is the molar volume of the liquid. $P_{0}, \gamma$, and $V_{m}$, which are, respectively, $2.03 \mathrm{~Pa}, 1925 \mathrm{mN} / \mathrm{m}$, and $7.90 \times 10^{-6} \mathrm{~m}^{3} / \mathrm{mol}$ at $1773 \mathrm{~K}$, are evaluated from the data for pure liquid iron; ${ }^{28,31,32)} r$ is $5 \mu \mathrm{m}$, from Table $1 . P=2.03 \mathrm{~Pa}$ was obtained from these data. This value is considerably smaller than the standard atmosphere, $1.013 \times 10^{5} \mathrm{~Pa}$. Therefore, $1.013 \times 10^{5}$ $\mathrm{Pa}$ was used as $\Delta P^{\prime}$. The result obtained using Eq. (13) is shown in Fig. 6. The curve calculated considering both the wettability and pressure difference is in good agreement with the experimental results, although there is still a small deviation between the experimental data and the calculated curve. The lower calculated value than the experimentally obtained neck radius can be attributed to the estimated capillary size being bigger than the real one, as mentioned above, because a bigger capillary size causes less capillary force, i.e. less contracting force, as seen from Eq. (8). The presence of a few per cent of $\mathrm{SiO}_{2}$ in the alumina balls is 
unlikely to cause a bigger neck radius in the experiments than in the calculations, considering that the diffusion of oxygen in alumina ${ }^{16,19,20)}$ is higher than that in mullite, ${ }^{33)}$ although there are variations in the reference data. It is well known that the two parameters used in the equation for the neck growth of alumina balls at sintering in molten iron, wettability between alumina and molten iron and surface tension of molten iron, show a large scatter due to the slight amount of oxygen and other impurities in the sample and so on. The contact angle ranges roughly between alumina and molten iron from 110 to $140^{\circ},{ }^{30)}$ and the surface tension of molten iron at $1773 \mathrm{~K}$ from 1800 to $2000 \mathrm{mN} / \mathrm{m},{ }^{28)}$ which are extrapolated from the data above melting point of iron. Here, we simulated the effect of the scatters of surface tension of molten iron and wettability between alumina and molten iron on the neck growth of alumina balls in molten iron with Eq. (13). The results calculated by independently varying the contact angle and the surface tension in the range mentioned above are shown in Fig. 6. Grey area and light grey area around chain double-dashed line, i.e. the calculated result by considering the wettability and pressure difference, are for contact angle and surface tension, respectively. The scatter of contact angle changes the calculated neck radius by -9 to $+2 \%$. On the other hand, the scatter of surface tension show only a slight change of neck radius like less than $1 \%$. Thus, we found that the contact angle between alumina and molten iron affects the neck growth more than surface tension of molten iron. However, these effects does not explain the difference between the calculated neck radius and the experimentally obtained neck radius.

In order to apply our proposed model to the actual situation, i.e. sintering in the immersion nozzle, ferrostatic pressure should be included in the model. The ferrostatic pressure, $\Delta P^{\prime \prime}$, is calculated by (distance from surface of molten steel in mold to target position in immersion nozzle) $\times$ (density of molten steel $) \times($ gravity acceleration). In a similar way to the pressures caused by cavity, the ferrostatic pressure can be introduced into the equation as below.

$$
\begin{aligned}
& x=\left(\frac{a^{n} K \gamma_{\mathrm{S}} V_{0} D}{R T}\right)^{0.228} \\
& \left\{1+\left(\Delta P^{\prime \prime}+\Delta P^{\prime}-\frac{4 a \gamma_{\mathrm{L}} \cdot \cos \theta}{x^{2}}\right) \cdot \frac{a}{\pi \gamma_{\mathrm{S}}}\right\}^{0.228} \cdot t^{0.228} \ldots
\end{aligned}
$$

In the present work, the modelling of the neck growth of alumina balls in molten iron was conducted based on the concept of Knuppel et al. ${ }^{8)}$ and the experimental fact with glass balls and liquid mercury by Yaminsky et al., ${ }^{25)}$ i.e. a non-wetting liquid is spontaneously expelled from the gap between two particles immersed in the liquid to form a cavity around the contact zone. However, there is no evidence that a cavity is formed around the contact zone of alumina balls in molten iron. Therefore, the possibility of the cavity formation between alumina balls in molten iron was confirmed by evaluating the change of total interfacial/surface energy around the neck part in the formation of cavity. Figure 10 shows the schematic pictures of the gap between the alumina balls in molten iron. Two situations, that (a) a cavity is formed at the gap and (b) the gap is filled with molten iron, are considered in two dimensions. When the length (a)

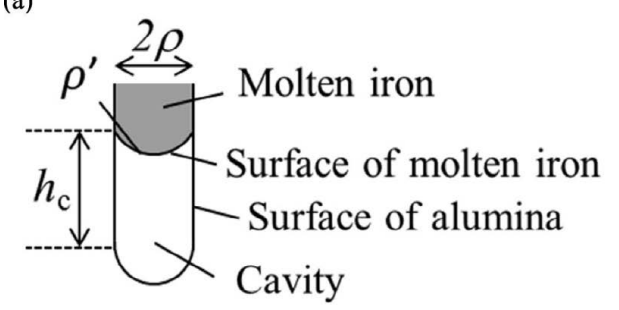

(b)

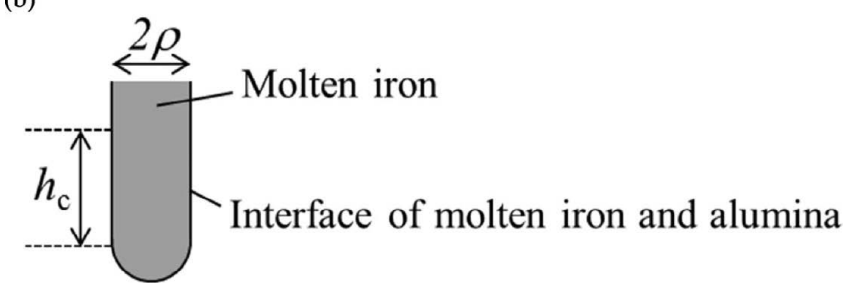

Fig. 10. Schematic diagrams of the gap between alumina balls in molten iron under the conditions: (a) a cavity is formed at the gap and (b) the gap is filled with molten iron.

of cavity and the length of meniscus are respectively expressed as $h_{\mathrm{c}}$ and $\rho^{\prime}$ in the situation (a), the total interfacial/ surface energy around the neck part is $\left(\pi \rho+2 h_{\mathrm{c}}\right) \gamma_{\mathrm{S}}+\rho^{\prime} \gamma_{\mathrm{L}}$. On the other hand, the total interfacial/surface energy around the neck part in situation (b) is $\left(\pi \rho+2 h_{\mathrm{c}}\right) \gamma_{\mathrm{S} / \mathrm{L}}$. The condition for the formation of cavity may be $\left(\pi \rho+2 h_{\mathrm{c}}\right) \gamma_{\mathrm{S} / \mathrm{L}}>$ $\left(\pi \rho+2 h_{\mathrm{c}}\right) \gamma_{\mathrm{S}}+\rho^{\prime} \gamma_{\mathrm{L}}$, viz. the cavity formation decreases the total interfacial/surface energy. When this equation is rearranged by isolating $h_{\mathrm{c}}$, the relation $h_{\mathrm{c}}>\left\{\gamma_{\mathrm{L}} \rho^{\prime} /\left(\gamma_{\mathrm{s} / \mathrm{L}}-\gamma_{\mathrm{s}}\right)-\right.$ $\pi \rho\} / 2$ is obtained. Thus, $h_{\mathrm{c}}>0$ in this relation satisfies the formation of cavity. By assigning values to $\gamma_{\mathrm{L}}, \gamma_{\mathrm{S}}$ and $\gamma_{\mathrm{S} / \mathrm{L}}$, the right side member becomes $\left(1.83 \rho^{\prime}-\pi \rho\right) / 2$. Because $\rho^{\prime}$ must be larger than the gap width $2 \rho,\left(1.83 \rho^{\prime}-\pi \rho\right) / 2$ should has a positive value, which means the cavity can be formed from the viewpoint of the change of total interfacial/surface energy around neck part.

The present work shows that the calculated results obtained by considering the capillary force and the cavity, which are caused by the non-wettability between liquid iron and the alumina ball, reproduce the experimental results on the neck growth of alumina balls at sintering in molten iron much better than those obtained by considering the interfacial tension between liquid iron and the alumina ball as a reflection of the change in the surroundings of the alumina ball, i.e. from an $\mathrm{Ar}$ atmosphere to molten iron, do. This means that not the interfacial tension between liquid iron and the alumina ball, but rather the non-wettability between liquid iron and the alumina ball affects the increase in the neck growth rate of alumina balls at sintering in molten iron. In addition, the capillary force generated by the non-wetting by liquid iron of alumina balls greatly promotes neck growth of alumina balls at sintering in molten iron, and the pressure difference between the cavity and the atmosphere does so to a small extent. It is therefore concluded that the increase in the rate of neck growth of alumina balls at sintering in molten iron compared with that under an $\mathrm{Ar}$ gas atmosphere is mainly attributable to the capillary force generated by non-wetting by liquid iron of alumina balls. 


\section{Conclusions}

The neck growths of alumina balls under an Ar gas atmosphere and in molten iron were investigated in the present work. In addition, an expression describing the neck growth of alumina balls at sintering in molten iron was developed by considering the interfacial properties, i.e. the interfacial tension and wettability, between molten iron and alumina. From these investigations, we drew the following conclusions.

(1) The necks of alumina balls in molten iron grow much faster than those under an Ar gas atmosphere.

(2) The calculated neck growth in molten iron, obtained using a model based on the effects of the capillary force caused by the non-wettability between molten iron and alumina pressing the alumina balls together and the difference between the vapor pressure in a cavity and the external pressure, agrees reasonably well with the experimental neck growth, i.e. the non-wettability and the pressure difference are the factors that increase the rate of neck growth of alumina balls in molten iron compared with that under an $\mathrm{Ar}$ atmosphere.

(3) In the two factors, the contribution of the pressure difference between the cavity and the atmosphere on the promotion of neck growth of alumina balls at sintering in molten iron is small in comparison with that of the capillary force caused by the non-wettability between molten iron and alumina.

\section{REFERENCES}

1) S. N. Singh: Metall. Trans., 5 (1974), 2165.

2) M. Uchimura, S. Ogibayashi, K. Yamaguchi, H. Honma and F. Yamaguchi: CAMP-ISIJ, 4 (1991), 219.

3) Y. Fukuda, Y. Ueshima and S. Mizoguchi: ISIJ Int., 32 (1992), 164.
4) K. Sasai, Y. Mizukami and H. Yamamura: Tetsu-to-Hagané, 79 (1993), 1067.

5) N. Shinozaki, N. Echida, K. Mukai, Y. Takahashi and Y. Tanaka: Tetsu-to-Hagané, 80 (1994), 748.

6) K. Mukai, R. Tsujino, I. Sawada, M. Zeze and S. Mizoguchi: Tetsuto-Hagané, 86 (1999), 307.

7) Y. Tsukaguchi, T. Kato, S. Watanabe, S. Ooga and T. Tanaka: Materia Jpn., 50 (2011), 27.

8) V. H. Knuppel, K. Brotzmann and N. W. Forster: Stahl Eisen, 83 (1965), 675.

9) T. B. Braun, J. F. Elliott and M. C. Flemings: Metall. Trans. B, 10B (1979), 171.

10) H. Yin, H. Shibata, T. Emi and M. Suzuki: ISIJ Int., 37 (1997), 936.

11) H. Ooi, M. Sekine and G. Kasai: Tetsu-to-Hagané, 59 (1973), 1078.

12) Y. Miki, H. Kitaoka, T. Sakuraya and T. Fujii: Tetsu-to-Hagané, 78 (1992), 431.

13) H. Ichinose and G. C. Kuczynski: Acta Mater., 10 (1962), 209.

14) L. Johnson and I. B. Cutler: J. Am. Ceram. Soc., 46 (1963), 541.

15) I. I. Spivak, R. A. Andrievskii and K. L. Chevasheva: Powder Metall. Met. Ceram., 7 (1968), 458,

16) A. H. Heuer: J. Eur. Ceram. Soc., 28 (2008), 1495

17) A. E. Paladino and R. L. Coble: J. Am. Ceram. Soc., 46 (1963), 133.

18) R. L. Coble: J. Am. Ceram. Soc., 41 (1958), 55.

19) T. Vasilos and R. M. Spriggs: J. Am. Ceram. Soc., 46 (1963), 493.

20) A. H. Heuer and K. P. D. Lagerlof: Philos. Mag. Letters, 79 (1999), 619.

21) R. M. German, P. Suri and S. J. Park: J. Mater. Sci., 44 (2009), 1.

22) B. C. Allen and W. D. Kingery: Trans. Metall. Soc. AIME, 215 (1959), 30.

23) J. G. Eberhart: J. Phys. Chem., 71 (1967), 4125

24) K. Nogi and K. Ogino: Can. Metall. Q., 22 (1983), 19.

25) V. V. Yaminsky, V. S. Yushchenko, E. A. Amelina and E. D. Shchukin: J. Coll. Int. Sci., 96 (1983), 301.

26) R. L. Coble: J. Appl. Phys., 41 (1970), 4798.

27) W. D. Kingery and M. Berg: J. Appl. Phys., 26 (1955), 1205.

$28)$ B. J. Keene: Int. Mater. Rev., 38 (1993), 157.

29) B. J. Keene: Int. Mater. Rev., 33 (1988), 1.

30) B. J. Keene: Slag Atlas 2nd ed., Verlag Sthleisen GmbH, Düesseldorf, (1995), 513.

31) R. Hultgren: Selected Values of the Thermodynamic Properties of the Elements, American Society for Metals, Metals Park, OH, (1973), 187.

32) T. Iida and R. I. L. Guthrie: The Physical Properties of Liquid Metals, Clarendon Press, Oxford, (1988), 71.

33) Y. Ikuma, E. Shimada, S. Sakano, M. Oishi, M. Yokoyama and Z. Nakagawa: J. Electrochem. Soc., 146 (1999), 4672. 